\title{
A System-based Paradigm of Drought Analysis for Operational Management
}

\author{
G. Tsakiris • I. Nalbantis $\cdot$ H. Vangelis $\cdot$ B. Verbeiren • \\ M. Huysmans • B. Tychon • I. Jacquemin • F. Canters • \\ S. Vanderhaegen • G. Engelen $\cdot$ L. Poelmans • \\ P. De Becker • O. Batelaan
}

Received: 24 April 2013 / Accepted: 23 October 2013 /

Published online: 28 November 2013

(C) Springer Science+Business Media Dordrecht 2013

\begin{abstract}
Conventionally droughts are studied in terms of their dimensions (severity, duration and areal extent), without specifying the affected system. The paper presents an innovative system-based approach for drought analysis, which can lead to rational decisions for combating drought. Concepts of water scarcity (drought, water shortage, aridity and desertification) are viewed within the perspective of this new approach. The paper focuses also on operational water management in the presence of drought. Starting from the needs for such management, the affected system is defined and the related quantities are identified. Also, sub-systems are considered which allow the establishment of the link between specific variables
\end{abstract}

G. Tsakiris $(\bowtie) \cdot I$. Nalbantis $\cdot H$. Vangelis

Centre for the Assessment of Natural Hazards and Proactive Planning, National Technical University of Athens, Heroon Polytechniou 9, 15780 Zografou, Greece

e-mail: gtsakir@central.ntua.gr

B. Verbeiren $\cdot$ M. Huysmans $\cdot$ O. Batelaan

Department of Hydrology and Hydraulic Engineering, Vrije Universiteit Brussel (VUB), Pleinlaan 2, 1050 Brussels, Belgium

B. Tychon · I. Jacquemin

Groupe Agrométéorologie, Département des sciences et gestion de l'environnement, Université de Liège (Ulg), Avenue de Longwy 185, 6700 Arlon, Belgium

F. Canters $\cdot$ S. Vanderhaegen

Department of Geography, Vrije Universiteit Brussel (VUB), Pleinlaan 2, 1050 Brussels, Belgium

G. Engelen $\cdot$ L. Poelmans

Unit Ruimtelijke Milieuaspecten, Vlaamse Instelling voor Technologisch Onderzoek (VITO), Boeretang 200, 2400 Mol, Belgium

P. De Becker

Instituut voor Natuur- en Bosonderzoek (INBO), Kliniekstraat 25, 1070 Brussels, Belgium

O. Batelaan

School of the Environment, Flinders University, GPO Box 2100, Adelaide, SA 5001, Australia 
and drought. Some drought characterisation methods are particularly suited for the systemic approach. Finally drought is considered as a natural hazard phenomenon and its consequences are discussed. Each physical sub-system can be improved by a variety of measures aiming at decreasing its vulnerability towards drought, so that the drought risk is mitigated. It is concluded that the clear definition of the affected system on the spatial and temporal scales can significantly contribute to the rational management for combating drought.

Keywords Drought - Water scarcity · Water shortage - Systemic approach · System vulnerability Drought risk

\section{Introduction}

Governments and international organisations are focusing their attention on the increasing threat of water stress in most regions of the world. Although this threat is primary exerted on the water deficient countries, there are signs that it may soon affect water sufficient, developed countries of the North.

According to the Commission of the European Communities (2007), droughts have dramatically increased in number and intensity in the European Union over the last three decades increasing the number of affected people by almost $20 \%$. It is estimated that the cost of droughts in Europe during the last 30 years is 100 billion Euros.

Although for all, drought is understood as a natural recurring phenomenon, it lacks a single and widely accepted definition. The main reason for this is the fact that since drought affects practically all sectors of the economy, it does so in such a variety of ways so that each sector establishes its own criteria for identifying and characterising each drought event, therefore having virtually its own concept of drought. Another reason for this diversity is the fact that drought occurs in quite different timing, severity and consequences even in the same sector which is affected by drought.

Obviously drought is the most complex natural hazard phenomenon. It is difficult to detect its onset and its termination, its severity and its areal extent. This led scientists to characterise drought as a "creeping natural hazard" (Wilhite 1993).

An operational definition of drought adopted by several competent groups in the drought academic society is that drought is the recurrent regional phenomenon characterised by a temporary severe decrease of water availability, deviating from normal conditions, over a significant period of time affecting a large territorial area. Drought is initiated mostly by deficient precipitation and is considered as a natural phenomenon related to the climatic variability in a region.

Although this definition seems sound and useful for developing drought preparedness plans it contains high ambiguity due to the terms "severe decrease", "significant period" and "large region", which also introduce subjectivity to the definition (Rossi et al. 1992).

There are numerous other definitions of drought, some of which are tailored for specific sectors of the economy, specific climatic regions and specific conditions affecting the droughtprone area (Correia et al. 1991; Tate and Gustard 2000; Wilhite and Glantz 1985).

It is the aim of this paper to clarify the key concepts related to drought and permanent or temporary water scarcity conditions. The approach adopted in this paper is the systemic approach, whereas the methodology of analysis is the methodology of risk assessment for natural hazard events. 


\section{Concepts and Definitions}

Some key concepts used when water is insufficient are defined. The importance of deficient water availability lies in its impacts. Therefore from the numerous definitions of the terms used, the "operational" rather than the "conceptual" definitions are adopted in this study.

The general term describing the stress conditions due to lack or deficiency of water is called water scarcity. Aridity is a natural environment imbalance in the water availability characterising the climatic conditions of a region. In contrast drought is a natural but temporary imbalance of water availability caused mainly by low precipitation and thus resulting in lower availability of water resources.

Desertification and water shortage are mainly caused by human induced causes and they represent permanent and temporary imbalance in the water availability, respectively. Desertification is widely known as the process of land degradation and deterioration of its productivity, including the damage caused to ecosystems, whereas water shortage is the deficit of water supply to meet the demands and is mainly caused by inappropriate use of water resources or man-made changes. However, in most of the cases water shortage is caused or initiated by intense drought episodes.

It is important to note that water scarcity is not only a quantitative concept but it affects and interacts to a great extent with quality matters. It has been observed that in most of the cases limited water availability leads to deterioration of water quality.

From the above it can be deduced that the water scarcity associated with aridity or desertification calls for engineering and management measures that produce conservation and augmentation of water resources. On the contrary water scarcity caused by droughts or water shortage requires the development and the implementation of Preparedness and Contingency Plans.

Temporary water scarcity (that is drought and/or water shortage) is not generally directly dependent on the aridity regime of the area. However the perception of these conditions in a dry area and the anticipated impacts are much more profound resulting in more adverse consequences when compared with the same event in a temperate region. Therefore, if the assessment of these phenomena puts emphasis on the consequences both the climatic regime (aridity) and the temporary deficiency (drought/water shortage) should be simultaneously considered.

Using an "operational" definition of temporary water scarcity, the critical term of water availability (falling below a certain threshold for a substantial period of time) should be defined and the characteristics of the phenomenon should be described by specifying the commencement, termination, intensity, total magnitude and areal extent of the phenomenon. In fact it is useful to know the temporal and spatial evolvement of each episode of water scarcity.

Conventionally drought may be treated as a meteorological, hydrological or agricultural phenomenon. In each of these expressions the variable representing "water availability" and the selected thresholds related to water availability are different. For instance drought may be determined by measuring the inflow to a reservoir of a water supply system or by the precipitation recorded in a number of meteorological stations in the watershed under study. It is therefore difficult to find a common basis for assessing drought. However in a particular system located in a certain region, relationships between meteorological on one hand (initiating cause) and the subsequent hydrological and agricultural drought on the other may be achieved. The most commonly used variables representing water availability in the various expressions of drought are: (1) Precipitation and evapotranspiration for meteorological drought; (2) streamflow, reservoir storage, recharge of aquifers, discharge from aquifers and base flow for hydrological drought; (3) soil water supply for agricultural drought. 
However it should be stressed that apart from the different expressions of drought the phenomenon/hazard is actually the same and it is basically meteorological according to the convention that the hydrological cycle starts from atmospheric water.

It should be noted that another expression of drought, the socio-economic drought (Grigg and Vlachos 1989; Mishra and Singh 2010) is not adopted in this study, since it involves apart from natural causes, human induced causes (e.g. water demand).

\section{Systemic Approach}

\subsection{The Problem and Motivation for a New Approach}

As mentioned in previous section, this paper focuses on operational aspects of drought and water scarcity. In such context, any authority or organisation specialising in water resources management of a certain area is interested to know if the whole or predefined parts of the area are in a state of drought or not. Thus, the boundary of the area of interest is expected to be fixed and known in advance. Yet, such an area is not homogeneous with respect to hydrological processes involved. One may discern a number of interacting elements within it, e.g. hillslopes and watercourses, the vadose zone and aquifers to mention but a few. It becomes evident that a spatial entity with fixed boundaries and interacting elements would significantly contribute to solving drought-related operational management decisions. Since the features of such an entity constitute the main properties of a system, it is natural to adopt the systemic approach.

In many of the currently available drought approaches, the spatial extent of the area under drought is left to vary in time. Such information, although useful in scientific research, is practically useless at the operational level. Questions such as "What is the spatial distribution of the area under drought within the broader area of responsibility of an authority" are meaningless.

Another problem of the conventional approaches is that these vaguely refer to a part of the hydrological cycle and avoid the precise delineation of the area or volume affected. Yet, operational constraints may impose the common consideration of both surface and soil water; how then could one characterise drought and what variables could use for this characterisation? The need to resort to the concept of a system with fixed and known boundaries becomes evident. The kind of variables to be used has to be defined at a second stage.

The above issues led us propose an innovative approach to the typology of drought and water scarcity which will be based on the concept of systems, as described below.

\subsection{The Water System}

For integrated water resources management the definition of the concept of the water system is of utmost importance. A water system can be defined as the entity expanding over a geographical area which includes all watersheds and groundwater recharge areas together with all water consumption centres and ecosystems associated with the processes occurring in the natural (abiotic or biotic) and human sub-systems.

In Table 1 the role of variables for all the sub-systems is presented for both the natural system and the system under human intervention. These are referred to as determinants.

Obviously, as in any other system, the physical water system comprises a number of elements. For example, a catchment is divided in several territorial units (e.g. Thiessen polygons), each of which is represented by a unique meteorological station. In a similar way, the groundwater recharge area is divided into a number of units with the same precipitation and geomorphological/geological characteristics. 
Table 1 Classification of drought determinants within the frame of the systemic approach (in regular characters for the natural system and in italics for human intervention)

\begin{tabular}{|c|c|c|c|}
\hline \multirow[t]{2}{*}{ Sub-system } & \multicolumn{3}{|l|}{ Role of variable } \\
\hline & Input & State & Output \\
\hline $\begin{array}{l}\text { Lower Atmospheric } \\
\text { Layer }\end{array}$ & $\begin{array}{l}\text { Precipitation, Potential } \\
\text { evapotranspiration } \\
\text { (incoming) }\end{array}$ & Air humidity & $\begin{array}{l}\text { Precipitation, Potential } \\
\text { evapotranspiration (outgoing), } \\
\text { Dew capture }\end{array}$ \\
\hline Surface-water & $\begin{array}{l}\text { Precipitation, Water } \\
\text { transfer }\end{array}$ & $\begin{array}{l}\text { Surface water storage, } \\
\text { Snow pack water } \\
\text { equivalent }\end{array}$ & $\begin{array}{l}\text { Surface runoff, Actual } \\
\text { evapotranspiration, Infiltration, } \\
\text { Water abstraction }\end{array}$ \\
\hline $\begin{array}{l}\text { Upper Unsaturated } \\
\text { zone }\end{array}$ & $\begin{array}{l}\text { Infiltration, Irrigation } \\
\text { water, Lateral water } \\
\text { inflow }\end{array}$ & Soil water & $\begin{array}{l}\text { Subsurface runoff, Percolation, } \\
\text { Sub-surface drainage } \\
\text { Lateral water outflow }\end{array}$ \\
\hline $\begin{array}{l}\text { Lower Unsaturated } \\
\text { zone }\end{array}$ & $\begin{array}{l}\text { Percolation, Artificial } \\
\quad \text { recharge }\end{array}$ & Soil water & Groundwater recharge \\
\hline Groundwater & $\begin{array}{l}\text { Groundwater recharge, } \\
\text { Artificial recharge }\end{array}$ & $\begin{array}{l}\text { Groundwater } \\
\text { head (level) }\end{array}$ & $\begin{array}{l}\text { Baseflow, Spring flow, Water } \\
\text { abstraction }\end{array}$ \\
\hline
\end{tabular}

An element of the system is under drought condition if it faces a sustained natural water input deficiency in relation to its normal conditions for a significant period of time.

Drought of the water system as a whole is characterised by the phenomenon in which a critical number of elements of the system are under drought condition. Practically a type of weighted aggregation of the various elements of the system is performed for the overall characterisation of the system.

Critical issues of this approach in relation to drought events are the temporal and spatial scales of analysis.

Although fine temporal and spatial analysis of academic type can be useful for specific processes related to water deficiency, for most common applications, all involved parties are mainly interested in essential, meaningful, transparent and practical assessments. Bearing this in mind, a number of simplifying approaches have been proposed recently (e.g. Tsakiris et al. 2007) related to the issues: determinants for analysis, spatial and temporal scale of analysis, etc.

Coming back to Table 1, it is important to illustrate a representative time variation of input variables in selected sub-systems of the natural system. In Fig. 1, precipitation deficit, infiltration deficit and groundwater recharge deficit are presented on a monthly basis showing the expected time lag between these quantities. It is interesting to note that the groundwater recharge deficit occurs some months after the initial precipitation deficit.

\subsection{Spatial and Temporal Analysis}

Drought is conceived as a multidimensional phenomenon (with dimensions of severity, duration, areal extent) which is difficult to model for reaching meaningful management decisions. The simplifications proposed recently (PRODIM 2008; Tigkas et al. 2012; Tsakiris 2008) are meant to replace the above three dimensions by a unique dimension in an attempt to reach a practical way to assess the severity of drought and perform a meaningful frequency analysis. Besides, the approach that employs "drought events" may have difficulties in identifying temporal or spatial coherency of such events (Saadat et al. 2013). The watershed (in case of small area) or sub-basin (in case of a large river basin) is proposed to be used as the territorial unit for the meteorological drought analysis replacing the areal extent, whereas the 

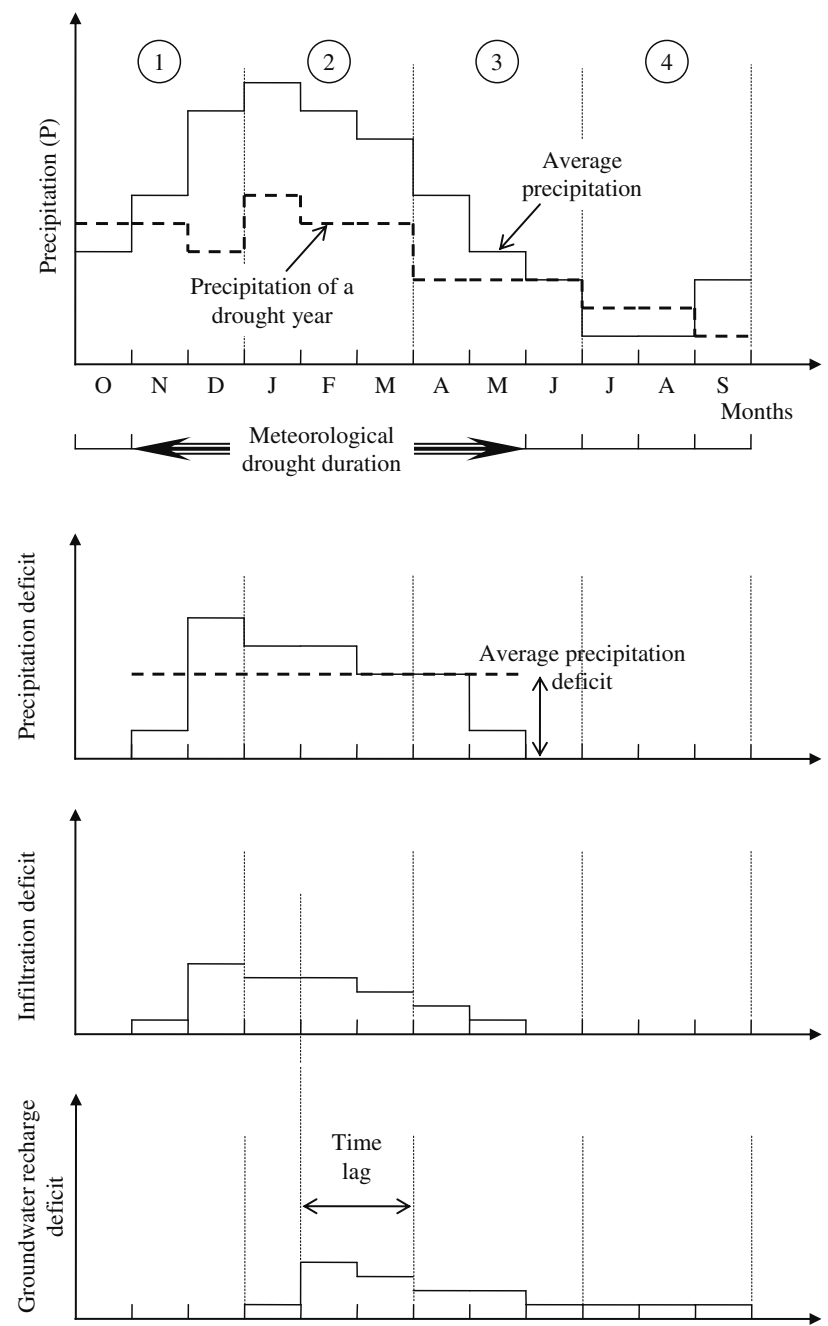

Fig. 1 A conceptual illustration of the transformation of precipitation deficit to groundwater recharge deficit

reference period is introduced for replacing the duration on the temporal scale. For standardisation purposes reference periods of 3, 6, 9 and 12 months starting from the onset of the hydrological year (October for most countries) are proposed.

If meteorological drought analysis is intended for groundwater drought analysis, the watershed or the sub-basin may be replaced by the groundwater recharge area which may not coincide with the watershed or the sub-basin. Also, if there is a special interest for the trimesters which do not commence in October each year, this analysis could be made for each trimester of the year and not necessarily in time aggregating fashion.

In conclusion, drought analysis should avoid small time steps and short periods for assessment because often these lead to misleading results. The practical proposal in this study is to use monthly temporal step for data analysis, and a reference period multiple to three consecutive months for the characterisation of the severity of each drought. 


\section{Drought Characterisation}

\subsection{Sub-systems of the Lower Atmospheric Layer and Surface Water}

The main cause of drought is the deficient precipitation, which is the main natural input into the physical system. This consists of the sub-systems depicted in Fig. 2. Therefore, for any analysis of drought and its consequences, the most significant variable is undoubtedly precipitation, which is at the same time the input and output of the lower layer of the atmosphere. Moreover, precipitation constitutes the input to the surface water sub-system thus being the most appropriate variable for assessing drought that refers to the lower atmosphere and surface water sub-systems or to the water system as a whole.

The assessment is conventionally carried out using drought indices. There are numerous indices which aim to assess drought severity by a single value only. A long list of drought indices with varying complexity has been used in many geographical areas of the world for various purposes. Some of the most popular indices which use only precipitation data are the Standardized Precipitation Index (SPI), the Rainfall Anomaly Index (RAI), the Standardized Anomaly Index (SAI), the Deciles, and the Percent of Normal. For a comprehensive review of these indices the reader can consult specialised reports (Heim 2002; Morid et al. 2006; Mishra and Singh 2010 and others).

Historically, the Run Method, the method of Deciles, SPI and RDI are the most popular indices currently used. These are briefly described below. In all of them, the system or subsystem area is divided into several territorial units representing common meteorological characteristics (e.g. through the Thiessen polygons method).

The Run Method allows an objective at site and regional drought identification and characterization, and therefore it represents a methodology for an analysis oriented to define best drought mitigation alternatives. The Run Method is based on the relationship between drought and negative runs in rainfall time series considering a critical threshold level (Yevjevich 1967; Rossi et al. 2003).

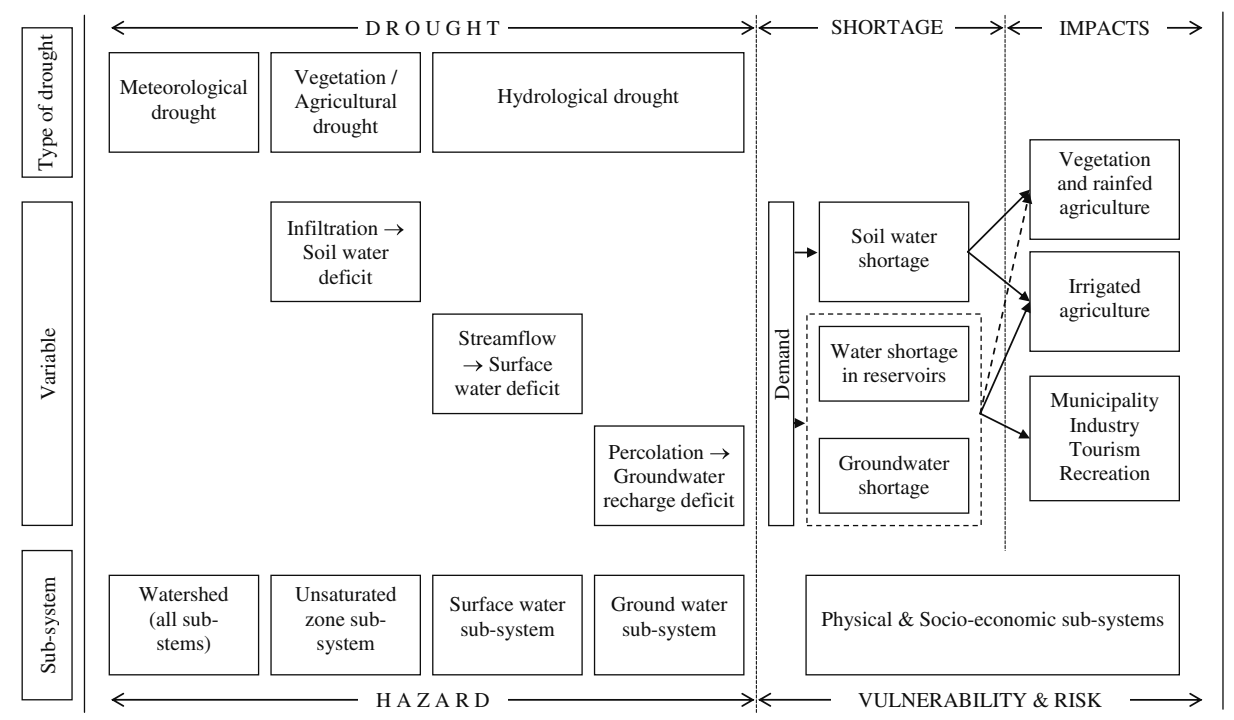

Fig. 2 Moving from drought hazards to drought consequences 
The Deciles index is a simple meteorological index in which the precipitation totals for the preceding 3 months are ranked against climatological records. The $i$-th decile is the precipitation amount not exceeded by the lowest $10 i \%$ of the precipitation occurrences. If the sum falls within the lowest decile of the historical frequency distribution of the 3-month precipitation totals then the region is considered to be under drought conditions (Kininmonth et al. 2000). The drought ends when: (i) the precipitation measured during the past month already places the 3-month total in or above the fourth decile, or (ii) the precipitation total for the past 3 months is in or above the eighth decile. A third rule was introduced to minimise the possibility of erroneous activation of the above rules due to small amounts of precipitation (Keyantash and Dracup 2002).

The Standardised Precipitation Index (SPI) was developed by McKee et al (1993) in order to serve as a "versatile tool in drought monitoring and analysis". The SPI calculation for any location is based on the long-term precipitation record for a desired period. This long-term record is fitted to a probability distribution, which is then transformed into a normal distribution so that the mean SPI for the location and desired period is zero (Edwards and McKee 1997). Thom (1958) found the gamma distribution to fit well to the climatological precipitation time series. Positive SPI values indicate greater than median precipitation, and negative values indicate less than median precipitation. Since SPI is normalized, wetter and drier climates can be represented in the same way. Although SPI can monitor wet periods, it is typically used to assess the length and magnitude of drought events.

According to SPI, a drought event occurs when the index continuously reaches an intensity of -1 or less. The event ends when the SPI becomes positive. Each drought event, therefore, has a duration defined by its beginning and end, and an intensity for each month that the event continues. Drought magnitude is the positive sum of the SPI for each month during the drought event (Hayes et al. 2007).

The SPI can track drought on multiple time-scales. It is usually computed with five running time intervals, i.e. 1-, 3-, 6-, 9-, and 12-months, but the index is flexible with respect to the period chosen. This powerful feature can provide an overwhelming amount of information unless researchers have a clear idea of the desired intervals. Moreover, being a standardized index, the SPI is particularly suited to compare drought conditions among different time periods and regions with different climatic conditions (Pandey et al. 2010; Shahid and Hazarika 2010).

The Reconnaissance Drought Index (RDI; Tsakiris and Vangelis 2005; Tsakiris et al. 2007) is used in several arid and semi-arid regions and is gaining ground, mainly due to its low data requirements and its high sensitivity and resilience (Farajalla and Ziade 2010; Asadi Zarch et al. 2011; Khalili et al. 2011; Kirono et al. 2011; Elagib and Elhag 2011). This drought index is based both on cumulative precipitation $(\mathrm{P})$ and potential evapotranspiration (PET), that is one measured and one calculated determinant. It can characterise drought linked to the lower atmosphere layer sub-system as well as the whole system. It uses sums of precipitation and potential evapotranspiration taken over the reference periods (see discussion in "Surface-water, Upper and Lower Unsaturated Zone, and Groundwater Sub-systems" Section). Two analytical forms of the index have been formulated, namely the normalised RDI and the standardised RDI. To tackle the problems of non-normality and the presence of zero sums of precipitation, appropriate techniques have been proposed (Tsakiris et al. 2008; Tigkas 2008). Positive values of standardised RDI indicate wet periods, while negative values indicate dry periods compared with the normal conditions of the area. The severity of drought events increases when RDI values are getting highly negative. Classes of drought severity (mild, moderate, severe and extreme) are related to reference periods. 
4.2 Surface-water, Upper and Lower Unsaturated Zone, and Groundwater Sub-systems

The decrease of precipitation discussed in the previous section naturally results in reduction of runoff and groundwater recharge as well as in reduction of storage either in the form of soil water or as groundwater reserves. For groundwater variables the reduction appears with delay. Historically, hydrological drought is defined as a decrease in the magnitude of the abovementioned hydrological variables below a certain threshold. Among these variables, streamflow is a composite variable since it embeds outputs of four different sub-systems, i.e. surface runoff from the surface water subsystem, subsurface runoff from the upper and lower unsaturated zone and baseflow from the groundwater sub-system. Hence, it can collectively characterise all these sub-systems. Another reason to choose streamflow for drought assessment is the fact that streamflow is a quantity of water that is available for direct use, possibly after regulation. As in cases with other sub-systems, drought is characterised in terms of three features: (1) its severity expressed by an appropriate drought index, (2) its time of onset and its duration, and (3) its areal extent.

The assessment of drought severity requires the use of an index which fulfils well-known criteria: operational usefulness, physical meaning, sensitivity to a wide range of drought conditions, applicability in all parts of the globe, quick response to changes due to drought and high availability of required data. However, the onset, duration and areal extent of drought raise serious problems if used at the operational level. This is the reason why the authors propose a methodology which eliminates two of the three aforementioned features. Thus the three-dimensional vector of drought determinants is reduced into a simpler one-dimensional quantity, i.e. severity.

A number of drought indices involving streamflow were proposed in the past such as the Palmer Hydrological Drought Index (PHDI), or Surface Water Supply Index (SWSI). These are data demanding and computationally intensive indices. To remedy this, the Streamflow Drought Index (SDI) has been proposed recently (Nalbantis and Tsakiris 2009). This is briefly described below.

Since drought is a gradually developing phenomenon the use of monthly time scale is quite sufficient. In the classical approach of drought analysis successive time intervals of various durations are used while in the proposed methodology, time is treated differently: (1) The first of October is considered as the beginning of the hydrological year, which is typical in Europe; (2) every 3 months (31st December, 31st March, 30th June, 30th September) a drought assessment is made regarding the time interval from the start of the hydrological year up to that time. The above treatment of time corresponds to situations with water resource systems possessing considerable total storage capacity.

Four overlapping time periods are defined within each hydrological year: OctoberDecember, October-March, October-June, and October-September (i.e., one complete hydrological year). These are herein referred to as the reference periods. The Streamflow Drought Index (SDI) uses cumulative streamflow volumes for each hydrological year and reference period. If the probability distribution of streamflow is skewed it can be transformed to normal by taking natural logarithms of cumulative streamflow. Based on SDI, drought severity classes are defined which are identical to those used in the drought indices SPI and RDI. Flow intermittency poses a serious computational problem only in case of a completely dry hydrological year (Nalbantis and Tsakiris 2009).

Other indices are the Drought Severity Index (DSI) of Pandey et al. (2008), the Standarized Hydrological Index (SHI) of Sharma and Panu (2010), the Standardized Streamflow Index (SSI) of Vicente-Serrano et al. (2012). Direct use of overlapping time intervals is found in Tabari et al. (2013). 
4.3 Upper Unsaturated Zone Sub-system

As mentioned earlier vegetation-agricultural drought is directly related to the deficiency of soil water which, in rainfed agriculture, causes loss in yield and the corresponding reduction of revenue. The sub-system of interest is the upper unsaturated zone while the lower unsaturated zone will not be examined since it is simply considered as an intermediate zone between the upper unsaturated zone and groundwater.

For this sub-system the key determinant is the part of precipitation which is infiltrating in the soil and contributes to crop production. A simple way of deriving this key determinant is the estimation of the effective precipitation. Effective precipitation (i.e. the part of precipitation that infiltrates) can be derived from the total using empirical equations, simplified tables, or detailed hydrological simulation.

Below are given some alternative simple methods for estimating effective precipitation from the monthly precipitation depth.

\section{a) Empirical method}

The earliest, though not entirely rational method for estimating effective precipitation is to use empirical relations as were used in the past. Using one of these popular equations the monthly effective precipitation is obtained as a percentage of total precipitation depending on the precipitation magnitude class. Simple equations of this type have been used extensively in water resources studies mainly in Mediterranean countries (Tsakiris 2006).

\section{b) U.S. Bureau of Reclamation (Stamm 1967)}

According to the method, the monthly effective precipitation is given as a range of increasing percentage of the monthly precipitation depth from a graph or table. For practical purposes the mean percentage at each class of precipitation may be used.

c) Use of a distributed hydrological model

The use of a distributed hydrological model produces information on surface runoff, infiltration, soil water storage, percolation, evapotranspiration and other related hydrological processes and variables. Continuous simulation at the level of each homogeneous hydrological unit can give a reasonably accurate estimation of monthly effective precipitation using the characteristics of this unit (Batelaan and De Smedt 2001, 2007).

A simpler semi-distributed conceptual model using the sub-basin as a hydrological response unit and the monthly temporal scale can be also used to account for the effective precipitation.

For rainfed agriculture less effective precipitation means less crop yield and therefore revenue loss. If no permanent damages are caused to the crops by drought, the severity of each episode expressed by a suitable drought index can be used together with some other variables to predict the yield loss and revenue loss. Keeping some of the influencing parameters constant, the prediction of yield can be achieved by the well known "water production functions" which are available in lumped (entire growing season) and dated (growing season divided in growth stages) forms.

In particular, dated water production functions have been presented for a variety of crops in the FAO documents (Steduto et al. 2012). Both multiplicative and additive water production functions have been proposed in the past (Tsakiris 1982; Tsakiris and Kiountouzis 1984). 
Apart from the deficient effective precipitation during a period of drought, an important issue is the determination of the "normal" crop production which cannot be attained due to drought. "Normal" production may be considered as the median of yearly productions during years without drought. However, a value with low downward deviation from the median can also be considered as normal production.

Another matter of interest is that the analysis should be carried out at each element of the agricultural sub-system, separately. An element in the agricultural system is a distinct spatial unit with a single crop and uniform other related characteristics such as hydraulic conductivity of soil. Obviously, each element exhibits a different vulnerability to drought. Some crops are very sensitive to water deficiency, while others can withstand severe droughts.

It is important to note that there are several factors which directly or indirectly influence the effect of drought on vegetation growth or agricultural production. Apart from the crop itself, the most important of them (with direct impact) are: the soil type, root depth, soil depth, soil surface slope, land-use pattern, elevation and groundwater conditions.

For any analysis of this kind the uncertainty of calculations is very high due to various possible interventions to the process: effective precipitation $\rightarrow$ crop production $\rightarrow$ revenue. Some of these are dependent on the characteristics of the treatment (e.g. fertilizers, pesticides etc) and some are dependent on the market (e.g. market values, imports etc).

In summary, this type of analysis of impacts of droughts in the agricultural sub-system should be treated with caution due to low accuracy of the expected results.

Finally, the analysis of drought in irrigated agricultural sub-system, is even a lot more complicated. This type of analysis starts with the deficiency of surface and groundwater and through the created water deficit and the prioritisation scheme of demand fulfilment, the anticipated loss in yield and the reduction of revenue can be estimated.

As normally practiced in case of a severe drought episode, one of the first sub-systems that are affected is the irrigated agriculture. In academic exercises performed recently in Mediterranean countries (PRODIM 2008), the priorities of demand fulfilment (from low to high) were (a) recreation facilities, (b) irrigated agriculture, (c) industry, (d) tourism, (e) municipalities. However, other priorities may be decided for other geographical areas, climatic zones and socio-economic conditions.

In conclusion, irrigated agriculture should be studied carefully in relation to losses in yield due to drought. In any case the prioritisation of demand fulfilment during a drought episode, needs a three dimensional optimisation in order to reach practical and meaningful results. The first dimension concerns the interannual distribution of water to each crop, the second the distribution of water between the elements of the sub-system (areas covered by each crop) and the third the distribution between irrigated agriculture and the other sectors of water consumption.

\subsection{Groundwater Sub-system}

Deficit in precipitation propagates to all sub-systems considered in previous sub-sections and ultimately influences the groundwater sub-system (Peters et al. 2003). Specifically, it lowers groundwater recharge which results in reduction of groundwater heads (or levels) and groundwater discharge (or baseflow). Hydrological variables that allow the quantification of groundwater sub-system drought are: groundwater recharge, groundwater level (or hydraulic head), spring discharge, and baseflow (Peters et al. 2006; Tallaksen et al. 2006; Chebud and Melesse 2012).

Reduction in the magnitude of hydrological variables such as those given above can be attributed either to natural or anthropogenic causes. 
The threshold method is most commonly used to define groundwater drought. The threshold is determined by equating the cumulative deficit below the threshold to a fixed percentage $c$ of the cumulative deficit below average. The constant $c$ is usually taken 0.30 (Peters et al. 2003). This is applicable to all related variables that represent water volumes passing through the sub-system (e.g. baseflow). For such variables the Sequent Peak Algorithm (SPA) can also be applied. Both methodologies help to define drought events and the characteristics thereof (total deficit, start and end time, duration, and mean and maximum intensity). However, in the case of a groundwater sub-system state variable such as the groundwater level, neither the classical threshold method nor SPA are applicable. To overcome this, a variant of the threshold method has been proposed in the past (Peters et al. 2003), which makes use of average values instead of accumulated downward deviations.

From the indices used to assess drought for the groundwater sub-system, the most common is the BaseFlow Index (BFI) (Gustard et al. 1992). This uses the threshold method for drought definition. The procedure applied to derive the index consists of the following steps: (1) a long time series of daily streamflow is processed, which allows for the extraction of baseflow for each day; any baseflow separation technique can be used at this stage (e.g. Institute of Hydrology 1980; Peters and van Lanen 2005); (2) baseflow duration curves are constructed for each hydrological year; (3) the master baseflow duration curve is constructed using the average values of frequency; (4) the $90 \%, 80 \%$ and $70 \%$ quantiles are drawn from the master flow duration curve; (5) drought is characterised as extreme when the average daily baseflow is below the $90 \%$ quantile, medium when it falls between the $90 \%$ and $80 \%$ quantiles, and weak for values between the $80 \%$ and $70 \%$ quantiles; beyond the $70 \%$ quantile non-drought conditions are considered.

Occurrence of drought is categorised in two ways. First, drought duration serves as the criterion to define a small number of duration classes for within-year droughts; then these are completed by the class of multiyear droughts in which duration exceeds 365 days. The second criterion is seasonality, in which each drought event is classified in a specific season; the definition of seasons within each hydrological year is prerequisite for this criterion (Peters et al. 2003).

The Drought Severity Index (DSI) is defined as the ratio of the total deficit volume in a specific drought period and the duration of that drought period. Dividing the Drought Severity Index by the average long-term baseflow helps derive the Standardized Baseflow Drought Severity Index (SBDSI). This allows for comparisons between different locations where baseflow is estimated from total discharge measurements (e.g., in different sub-basins, or groundwater sub-systems) (Fendekova and Fendek 2012).

The Groundwater Resource Index (GRI) has been proposed recently (Mendicino et al. 2008). This is derived from a simple distributed water balance model which is a modified version of the distributed monthly water balance model of Mendicino and Versace (2007). This is based on ideas proposed by Thornthwaite and Mather (1955). Variables involved are precipitation, evapotranspiration, snow accumulation and snowmelt, root zone surplus, surface flow, groundwater recharge, groundwater detention or storage, groundwater discharge. The index is defined as the standardised groundwater storage.

From the above discussion it follows that BFI, DSI, SBDSI are all defined on the basis of the subsystem output, i.e., baseflow, whereas GRI is based on the sub-system state (groundwater storage).

\section{Drought as a Natural Hazard}

Droughts, as all the other natural hazards, are a potential threat for a system or sub-system. They are recurrent phenomena affecting a system/sub-system with the potential to create stress or to initiate failure or damages to its elements. 
As drought hazard is a potential threat, the real threat is the risk associated with the drought hazard given the exposure, the coping capacity and robustness of the affected system. The lack of capability of the system to withstand the hazard and its consequences is usually referred to as vulnerability of the system in relation to the hazard.

The vulnerability of a system towards drought can be decomposed in the vulnerability of each element of the system. It is logical to expect that each element of the system may have different vulnerability from its adjacent element due to the different factors characterising its ability to withstand drought. Therefore a more systematic approach for the vulnerability of the affected system is to start by analysing the vulnerability of each of its elements or group of elements with the same characteristics and then attempt an integration over space (throughout the whole system) and hazard magnitudes (Tsakiris 2007a).

In general, the vulnerability of a system towards drought is mainly dependent on:

- the state of the system

- the availability of alternative sources of water (including emergency water supplies)

- the strategic preparatory measures and predicting drought severity

- the effectiveness of demand reduction measures

- the improvements of the conveyance and distribution networks

- the effective prioritisation of demand fulfilment

- the cooperation of all interested parties and the society

The vulnerability reduction of a system is the most important step for reducing the drought risk. This can be achieved by a well structured Preparedness Plan, formulated long before the drought episode with the participation of all interested parties.

For the calculation of risk for each drought scenario the consequences on the system under study should be estimated. As known, the consequences are very much dependent, not only on the severity of drought (magnitude of hazard), but on the vulnerability of the system and the primary state of the system at the initiation of the drought event. For example, the consequences of a yearly drought on a deep groundwater system might be negligible if the initiation of the drought event coincides with a very high groundwater head created by previous rainy years.

This implies that it is difficult to formulate direct functions between drought severity and consequences. Figure 2 tries to establish the link between the traditional typology and analysis of droughts and the proposed systemic approach. The causative factor which is the drought hazard is first classified (left part of the figure): drought types (upper left) are associated with sub-systems (lower left) and variables (middle left). Moving from left to right the water shortage in each one of the affected sub-systems is found which is created by water deficit in relation to water demand imposed on that sub-system. Shortage is then related to impacts to various water use sectors (right part). The last two stages of analysis (water shortage and impact assessment) collectively allow also the estimation of the related vulnerability and risk. Especially for the rainfed agriculture, the vegetation/agricultural drought can be directly associated to the consequences.

Important factor closely related to vulnerability is also the capacity of the system to recover, known as resilience. For practical purposes this factor can be considered as part of vulnerability of the system.

Despite of the difficulties to estimate the consequences, there have been methods for their gross estimation (monetary or simply quantitative). These methods give rough estimates of consequences or the range of consequences.

Finally, an important issue towards the estimation of consequences is whether the drought event is an isolated event occurring during a single year or it is a part of a multiyear drought, in which case the consequences are expected to increase (Tsakiris et al. 2010). 
In order to reduce the drought risk one can reduce the vulnerability of the affected system by improving its conditions, by decreasing the magnitude of the water shortage (and therefore its consequences) and by improving the public awareness and public capacities (that is the so-called "social factor").

Considering the geographical area of Europe the impacts of drought and the resulting water shortage can be economic, environmental and social. These impacts can be either direct or indirect. They can be immediate or delayed, tangible or intangible. A comprehensive list of possible drought impacts is presented elsewhere (e.g. Rossi et al. 2007).

The common approach for studying natural hazards and estimating the risk affecting a certain system is the description of the hazard by a certain probability density distribution and then, through the vulnerability of the system, to estimate the risk. These terms are clarified by Tsakiris et al. (2009) in a context dealing with floods. Therefore the risk accounts for the anticipated losses/damages for an event having a certain probability of occurrence.

The synthesis of the three dimensions of drought into one and the definition of the system in spatial scale allows for a frequency analysis of droughts referring to a certain reference period. This facilitates the use of concepts such as "the return period" which are familiar to the wide audience of engineers and scientists working for the analysis of extreme events.

In this analysis the average risk over a long period of years is also of great importance since it represents the average level of losses/damages per year from all possible drought events which may occur during this long period. This average risk is also referred to as "annualised risk" (Tsakiris 2007a, b).

For the effective calculation of the risk of the entire system, a certain disaggregation should be attempted and then all individual results can be summed up. It is also of utmost importance to reproduce the relatively small period of years, which is usually available as a historical record, so that a very long period for study is available and a sufficient number of drought events can be analysed.

For the agricultural sector, the proposed procedure may be also used for identifying the Less Favoured Areas (LFA) in Europe based on the criterion of 'Climate Variability and Impact on Agriculture' (JRC - European Commission 2007)

It is important to remember that the estimation of impacts and the risk in various sectors of the economy is a difficult task and in many cases cannot be approached by one-to-one functions. In many cases, due to the high uncertainty, the impacts cannot be treated as single value estimates, but can be treated as fuzzy quantities. There are also cases in which impacts cannot be estimated at all. In this latter case, the risk can be defined in a different way such as the exceedance probability over a certain magnitude of the related drought hazard.

\section{Concluding Remarks}

The paper presented a system-based typology of drought and water scarcity concepts. Several components related to drought were defined using the systemic approach for management decisions. Drought was defined as a recurrent natural phenomenon characterised by a significant water deficiency affecting a system for a significant period of time.

Further the paper reviewed the drought characterisation methods for all categories of drought: meteorological, hydrological (streamflow and groundwater) and vegetation/agricultural.

Finally drought was analysed as a natural hazard and the vulnerability of each system and the risk associated with drought were briefly discussed.

In the analysis and characterisation of drought and the associated risk, the key innovative aspect of this paper is the clear definition of the systems which are affected, in both spatial and 
temporal scales. The main conclusion of this paper is that it proposes a comprehensive, though practical and meaningful, procedure for analysing droughts and assessing drought risk.

Finally the annualised drought risk can be the main criterion for identifying the most drought prone areas in a region.

Acknowledgments This research (GRoWaDRISK project, 2012-2016) frames within the Belgian Science Policy Office (BELSPO) programme 'Science for Sustainable Development'.

\section{References}

Asadi Zarch MA, Malekinezhad H, Mobin MH, Dastorani MT, Kousari MR (2011) Drought Monitoring by Reconnaissance Drought Index (RDI) in Iran. Water Resour Manag 25(13):3485-3504

Batelaan O, De Smedt F (2001) WetSpass: a flexible, GIS based, distributed recharge methodology for regional groundwater modelling. In: Gehrels H, Peters J, Hoehn E, Jensen K, Leibundgut C, Griffioen J, Webb B, Zaadnoordijk W-J (eds) Impact of human activity on groundwater dynamics. IAHS Publ. No. 269, 2001, pp $11-17$

Batelaan O, De Smedt F (2007) GIS-based recharge estimation by coupling surface-subsurface water balances. J Hydrol 337(3-4):337-355. doi:10.1016/j.jhydrol.2007.02.001

Chebud Y, Melesse A (2012) Spatiotemporal surface-groundwater interaction simulation in South Florida. Water Resour Manag 26(15):4449-4466

Commission of the European Communities (2007) Communication from the Commission to the Council and the European Parliament "addressing the challenge of water scarcity and droughts in the European Union", Brussels

Correia FN, Santos MA, Rodrigues RR (1991) Reliability in regional drought studies. In: Ganoulis J (ed) Water Resources Engineering Risk Assessment, NATO ASI Series, Vol G 29, Berlin, pp 43-62

Edwards DC, McKee TB (1997) Characteristics of 20th century drought in the United States at multiple time scales. Climatology Report Number 97-2, Colorado State University, Fort Collins, Colorado

Elagib NA, Elhag MM (2011) Major climate indicators of ongoing drought in Sudan. J Hydrol 409(3-4):612-625

Farajalla N, Ziade R (2010) Drought frequency under a changing climate in the Eastern Mediterranean: the Beka'a Valley, Lebanon. Geophys Res Abstr 12 EGU2010-11653

Fendekova M, Fendek M (2012) Groundwater drought in the Nitra River basin - Identification and classification. J Hydrol Hydromech 60(3):185-193

Grigg N, Vlachos E (1989) Drought water management. A report, Colorado State University

Gustard A, Bullock A, Dixon JM (1992) Low flow estimation in the United Kingdom. Institute of Hydrology Report Number 108. ISBN 0948540451

Hayes MJ, Alvord C, Lowrey J (2007) Drought indices. Feature Artic Intermt W Clim Summ 3(6):2-6

Heim RR (2002) A review of twentieth-century drought indices used in the United States. Bull Am Meteorol Soc 83(8):1149-1165

Institute of Hydrology (1980) Low Flow Studies Report, 3 volumes. Institute of Hydrology, Wallingford

JRC-European Commission (2007) Common biophysical criteria for defining areas which are less favourable for agriculture in Europe. In: Eliasson A, Terres JM Bamps C (eds). Proc. Expert Meeting, Ispra Italy 19-20 April 2007. EC-JRC / IES, Luxembourg, p 80

Keyantash J, Dracup JA (2002) The quantification of drought. An evaluation of drought indices. Bull Am Meteorol Soc 83(8):1167-1180

Khalili D, Farnoud T, Jamshidi H, Kamgar-Haghighi AA, Zand-Parsa S (2011) Comparability analyses of the SPI and RDI meteorological drought indices in different climatic zones. Water Resour Manag 25(6):1737-1757

Kininmonth WR, Voice ME, Beard GS, de Hoedt GC, Mullen CE (2000) Australian climate services for drought management. In: Wilhite DA (ed) Drought, a global assessment. Routledge, London, UK, pp 210-222

Kirono DGC, Kent DM, Hennessy KJ, Mpelasoka F (2011) Characteristics of Australian droughts under enhanced greenhouse conditions: results from 14 global climate models. J Arid Environ 75(6):566-575

McKee TB, Doesken NJ, Kleist J (1993) The relationship of drought frequency and duration to time scale. Proceedings of the Eighth Conference on Applied Climatology, American Meteorological Society. Anaheim (CA), 17-22 January 1993, AMS, pp 179-184

Mendicino G, Versace P (2007) Integrated drought watch system: a case study in Southern Italy. Water Resour Manag 21:1409-1428 
Mendicino G, Senatore A, Versace P (2008) A Groundwater Resource Index (GRI) for drought monitoring and forecasting in a mediterranean climate. J Hydrol 357:282-302

Mishra AK, Singh VP (2010) A review of drought concepts. J Hydrol 391(1-2):202-216

Morid S, Smakhtin V, Moghaddasi M (2006) Comparison of seven meteorological indices for drought monitoring in Iran. Int J Climatol 26(7):971-985

Nalbantis I, Tsakiris G (2009) Assessment of hydrological drought revisited. Water Resour Manag 23(5):881-897

Pandey RP, Mishra SK, Singh R, Ramasastri KS (2008) Streamflow drought severity analysis of Betwa River System (India). J Water Resour Manag 22(8):1127-1141

Pandey RP, Pandey A, Galkate Ravi V, Byun H-R, Mal BC (2010) Integrating hydro-meteorological and physiographic factors for assessment of vulnerability to drought. Water Resour Manag 24:4199-4217

Peters E, van Lanen HAJ (2005) Separation of base flow from streamflow using groundwater levels - illustrated for the Pang catchment (UK). Hydrol Process 19:921-936

Peters E, Torfs PJJF, van Lanen HAJ, Bier G (2003) Propagation of drought through groundwater - a new approach using linear reservoir theory. Hydrol Process 17(15):3023-3040

Peters E, Bier G, van Lanen HAJ, Torfs PJJF (2006) Propagation and spatial distribution of drought in a groundwater catchment. J Hydrol 321:257-275

PRODIM (2008) In: Tsakiris G (ed) Proactive Management of Water Systems to Face Drought and Water Scarcity in Islands and Coastal Areas of the Mediterranean (PRODIM) - final report. CANaH - Publication, Athens, p 445

Rossi G, Benedini M, Tsakiris G, Giakoumakis S (1992) On regional drought estimation and analysis. Water Resour Manag 6(4):249-277

Rossi G, Cacelliere A, Pereira LS, Oweis T, Shataniawi M, Zairi A (eds) (2003) Tools for drought mitigation in Mediterranean Regions. Kluwer Academic Publishers, The Netherlands, $357 \mathrm{p}$

Rossi G, Castignione L, Bonaccorso B (2007) Guidelines for planning and implementing drought mitigation measures. In: Rossi G, Vega T, Bonaccorso B (eds) Methods and tools from drought analysis and management, Ch 16, Springer, AA Dordrecht, The Netherlands 325-347

Saadat S, Khalili D, Kamgar-Haghighi AA, Zand-Parsa S (2013) Investigation of spatio-temporal patterns of seasonal streamflow droughts in a semi-arid region. Nat Hazards. doi:10.1007/s11069-013-0783-y

Shahid S, Hazarika MK (2010) Groundwater drought in the Northwestern Districts of Bangladesh. Water Resour Manag 24:1989-2006

Sharma TC, Panu US (2010) Analytical procedures for weekly hydrological droughts: a case of Canadian rivers. J Hydrol Sci 55(1):79-92

Stamm GG (1967) Problems and procedures in determining water supply requirements for irrigation projects. In: Hagan R et al (eds) Irrigation and agricultural lands. Monogr. No 11, American Society Agron. Madison, WI, pp 771-784

Steduto P, Hsiao TC, Fereres E, Raes D (2012) Crop yield response to water. FAO Irrigation and drainage paper 66. Food and Agriculture Organization of the United Nations, Rome (Italy), p 503

Tabari H, Nikbakht J, Hosseinzade P (2013) Hydrological drought assessment in Northwesterm Iran based on Streamflow Drought Index (SDI). Water Resour Manag 27:137-151

Tallaksen LM, Hisdal H, van Lanen HAJ (2006) Propagation of drought in a groundwater fed catchment, the Pang in UK. In: Demuth S (ed) FRIEND 2006 - Water resource variability: processes, analyses and impacts. IAHS Publ., 308, 128-133. Technical Report No. 1117

Tate EL, Gustard A (2000) Drought definition: a hydrological perspective. In: Voght JV, Somma F (eds) Drought and drought mitigation in Europe (advances in natural and technological hazard research). Kluwer Academic Publishers, Dordrecht, pp 23-48

Thom HCS (1958) A note on the gamma distribution. Mon Weather Rev 86:117-122

Thornthwaite CW, Mather JR (1955) The water balance climatology. Drexel Inst. of Technology, Centeron

Tigkas D (2008) Drought characterisation and monitoring in regions of Greece. Eur Water 23(24):29-39

Tigkas D, Vangelis H, Tsakiris G (2012) Drought and climatic change impact on streamflow in small watersheds. Sci Total Environ 440:33-41

Tsakiris G (1982) A method for applying crop sensitivity factors in irrigation scheduling. Agric Water Manag 5: $335-343$

Tsakiris G (2006) Hydraulic works: design and management, volume II: reclamation works. Symmetria Publications, Athens, $773 \mathrm{p}$

Tsakiris G (2007a) Practical application of risk and hazard concepts in proactive planning. Eur Water 19(20):47-56

Tsakiris $G$ (2007b) A paradigm for applying risk and hazard concepts on proactive planning: application of rainfed agriculture in Greece. Drought Management Guidelines - Technical Annex, 297-304

Tsakiris G (2008) Uni-dimensional analysis of droughts for management decisions. Eur Water 23(24):3-11

Tsakiris G, Kiountouzis E (1984) Optimal intraseasonal irrigation water distribution. Adv Water Resour 7:89-92

Tsakiris G, Vangelis H (2005) Establishing a drought index incorporating evapotranspiration. Eur Water 9(10):3-11 
Tsakiris G, Pangalou D, Vangelis H (2007) Regional drought assessment based on the Reconnaissance Drought Index (RDI). Water Resour Manag 21(5):821-833

Tsakiris G, Nalbantis I, Pangalou D, Tigkas D, Vangelis H (2008) Drought meteorological monitoring network design for the reconnaissance drought index (RDI). In: Franco Lopez A (ed) Proceedings of the 1st International Conference "Drought management: scientific and technological innovations". Zaragoza, Spain: option Méditerranéennes, series A, no. 80, 12-14 June 2008, pp 57-62

Tsakiris G, Nalbantis I, Pistrika A (2009) Critical technical issues on the EU flood directive. Eur Water 25(26): $39-51$

Tsakiris G, Vangelis H, Tigkas D (2010) Assessing water systems vulnerability to multi-year droughts. Eur Water 29:21-29

Vicente-Serrano SM, López-Moreno JI, Beguería S, Lorenzo-Lacruz J, Azorin-Molina C, Morán-Tejeda E (2012) Accurate computation of Streamflow Drought Index. J Hydrol Eng 17(2):318-332

Wilhite DA (1993) The Enigma of drought (chapter 1, part one). In: Wilhite DA (ed) Drought assessment, management and planning: theory and case studies. Kluwer Academic Publishers, Norwell, pp 3-15

Wilhite DA, Glantz MH (1985) Understanding: the drought phenomenon: the role of definitions. Water Int 10(3): $111-120$

Yevjevich V (1967) An objective approach to definitions and investigations of continental hydrologic droughts. Hydrology Paper no. 23. Colorado State University, Fort Collins, CO 